\title{
Transradial approach for carotid artery stenting in a patient with severe peripheral arterial disease
}

\author{
Damian Maciejewski ${ }^{1}$, Piotr Pieniążek ${ }^{1}$, Łukasz Tekieli ${ }^{1}$, Piotr Paluszek ${ }^{1}$, Karolina Dzierwa1 ${ }^{1}$ Mariusz Trystuła², \\ Magdalena Wójcik-Pędziwiatr ${ }^{3}$, Piotr Podolec ${ }^{1}$
}

${ }^{1}$ Department of Cardiac and Vascular Diseases, Jagiellonian University, John Paul II Hospital, Krakow, Poland

2Department of Cardiovascular Surgery and Transplantology - Division of Endovascular Surgery, Jagiellonian University,

John Paul II Hospital, Krakow, Poland

${ }^{3}$ Department of Neurology, Jagiellonian University Medical College, Krakow, Poland

Postep Kardiol Inter 2014; 10, 1 (35): 47-49

DOI:10.5114/pwki.2014.41469

\begin{abstract}
A b stract
We present a case of a 73-year-old man with critical bilateral internal carotid artery stenosis, recent right-hemisphere stroke and severe peripheral artery disease in whom right internal carotid artery stenting (RICA-CAS) was performed successfully via a right transradial approach.
\end{abstract}

Key words: carotid artery stenting, radial approach, peripheral artery disease, stroke, embolic protection device.

\section{Introduction}

Stroke remains a major cause of morbidity and mortality. It is also a main cause of severe disability in adults [1]. Every year 75000 people in Poland suffer from stroke and it has been demonstrated that atherosclerotic carotid artery disease accounts for about $20 \%$ of all ischemic strokes [2].

The aim of modern treatment of carotid artery atherosclerosis is to inhibit the progression of the disease and, more importantly, to prevent stroke. With increasing operator experience, ongoing technical improvement in embolic protection devices (EPD) and stent design, carotid artery stenting (CAS) has emerged as an effective treatment associated with high efficacy and a low complication rate [3]. The transfemoral approach is commonly used for CAS; however, in cases of severe peripheral artery disease (PAD), the transradial access remains a viable alternative.

\section{Case report}

A 73-year-old man with a 9-day history of right hemisphere ischemic minor stroke was admitted to our institution due to a bilateral stenosis of the internal carotid artery revealed in duplex ultrasonography
(DUS) for further evaluation and treatment. Additional comorbidities included stable coronary artery disease, paroxysmal atrial fibrillation treated with oral anticoagulants, hypertension, hypercholesterolemia and severe PAD with occlusion of the right common iliac artery treated with suprapubic femoro-femoral bypass in 2005 (Figure 1). Admission DUS confirmed tight bilateral internal carotid artery stenosis with peak systolic velocity of $3.2 \mathrm{~m} / \mathrm{s}$ and end diastolic velocity of $1.1 \mathrm{~m} / \mathrm{s}$ on the right side. After consultation in the multidisciplinary team including a neurologist, vascular surgeon and interventional cardiologist, the patient was scheduled for transradial right internal carotid artery stenting (RICA-CAS) due to concomitant PAD. On the procedure day, a $7 \mathrm{Fr}$ arterial sheath was placed in the right radial artery. Catheterization of the right common carotid artery with a 5 Fr SIM1 diagnostic catheter (Boston Scientific) was unsuccessful; thus it was exchanged for a 5 Fr SIM2. A tapered steerable Jindo 0.035" guidewire (Cordis) was positioned at a distal segment of the right external carotid artery and the diagnostic catheter was exchanged for the 7 Fr Guider Softip XF Guiding Catheter (Boston Scientific) (Figure 2). The selective angiogram showed eccentric $80 \%$ stenosis of the right internal ca-

\section{Corresponding author:}

Damian Maciejewski MD, Department of Cardiac and Vascular Diseases, Jagiellonian University, John Paul II Hospital, 80 Prądnicka St, 31-202 Krakow, Poland, phone: +48 1261422 87, +48 609448 745, e-mail: damianmaciejewski@tlen.pl

Received: 6.02.2014, accepted: 18.02.2014. 


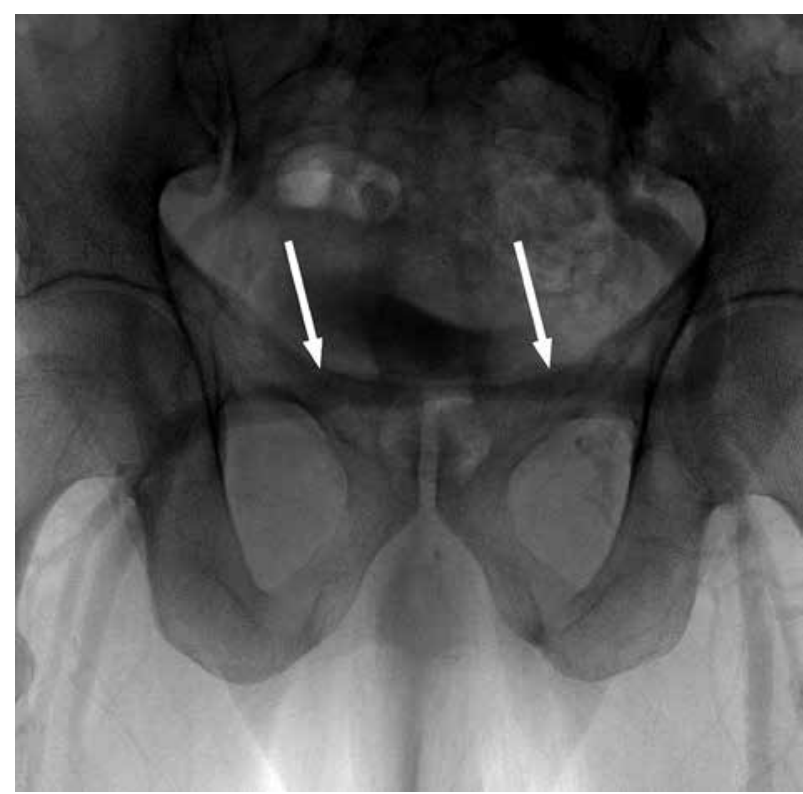

Figure 1. Suprapubic femoro-femoral bypass (arrows)

rotid artery (Figure 3). Over a SionBlue J 0.014" guidewire (Asahi), a 6 Fr Spider FX distal embolic protection device (ev3) was introduced and opened distally to the target lesion. A closed-cell design, self-expanding Carotid Wallstent $7 \mathrm{~mm} \times 30 \mathrm{~mm}$ (Boston Scientific) was implanted using the direct stenting technique. In the next step an Ultra-Soft $5 \mathrm{~mm} \times 20 \mathrm{~mm}$ dilatation catheter (Boston Scientific) was used for post-dilatation $(2 \times 10 \mathrm{~atm} /$ $10 \mathrm{~s}$; Figure 4) with an optimal angiographic result (<20\% residual stenosis without dissection, Figure 5). The peri-

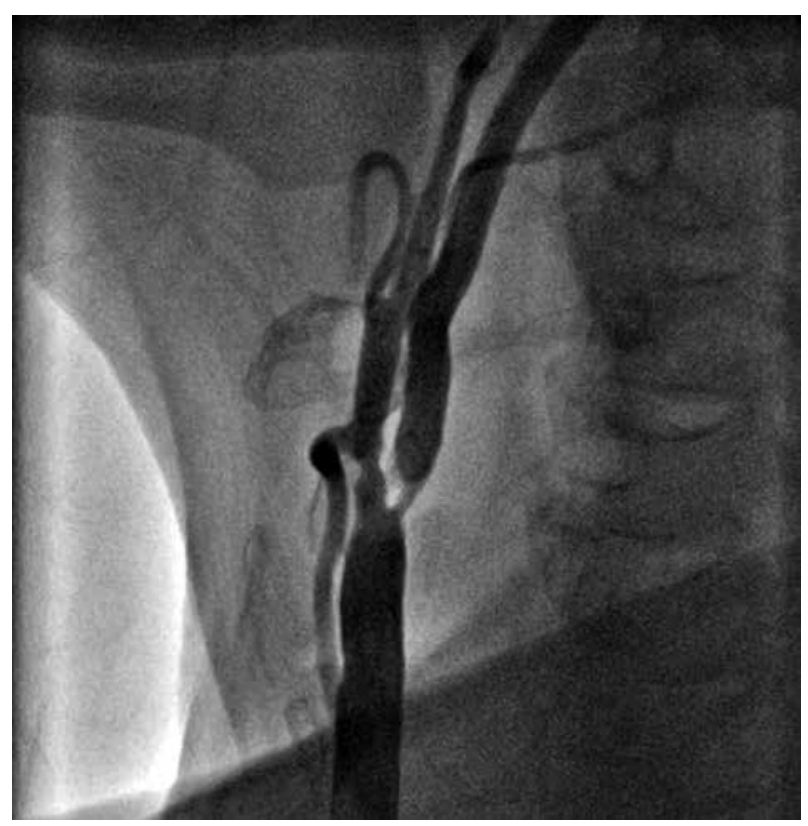

Figure 3. Selective angiography confirming critical ostial stenosis of the right internal carotid artery

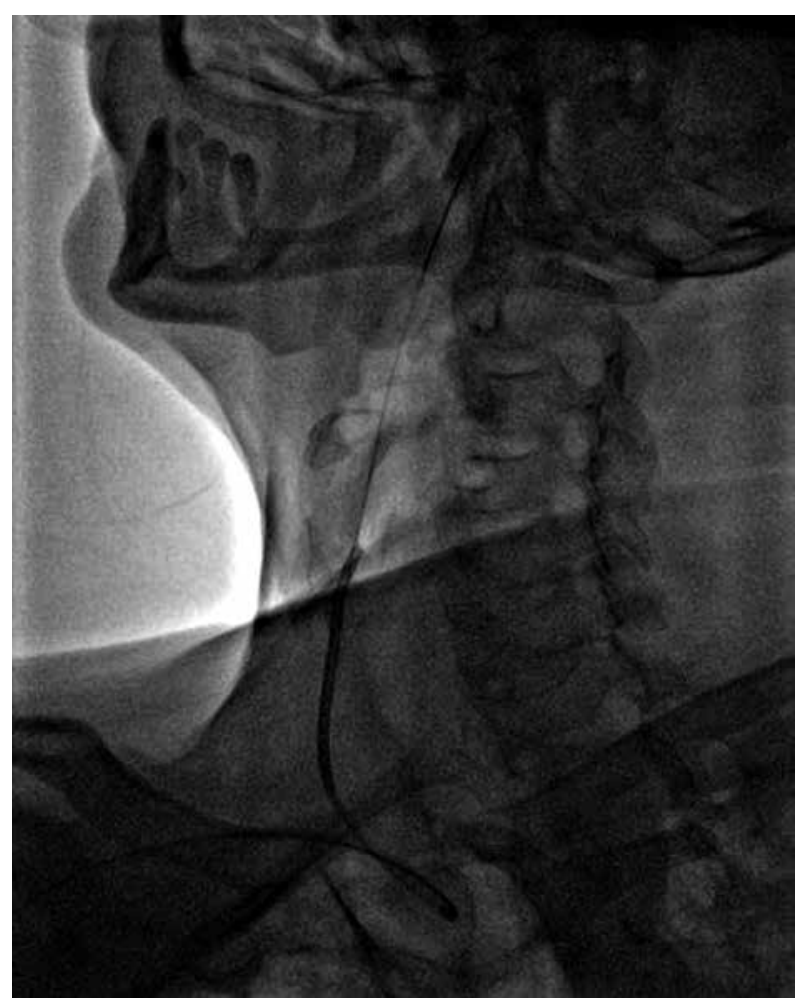

Figure 2. Successful cannulation of the right common carotid artery with $7 \mathrm{Fr}$ Guider Softip Guiding Catheter via the right radial artery

and postprocedural period was uneventful and the patient was discharged from hospital the next day. Neither new cerebral events nor restenosis were revealed during 6-month follow-up.

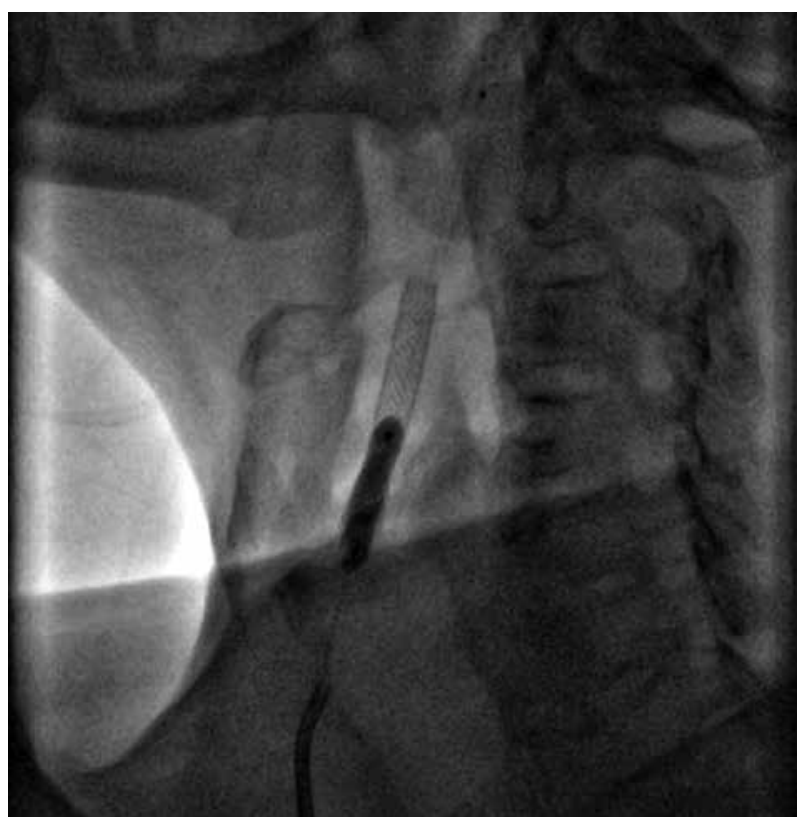

Figure 4. Self-expanding Carotid Wallstent $7 \mathrm{~mm}$ $\times 30 \mathrm{~mm}$ post-dilatation with $5.0 \mathrm{~mm} \times 20 \mathrm{~mm}$ balloon 


\section{Discussion}

It was shown that CAS may be a fair alternative to the carotid endarterectomy and it is considered safe and effective when performed by well-trained operators in high-volume centers $[4,5]$. Transfemoral access is the most common access for the CAS procedure; however, in severe aorto-iliac disease it can be unfeasible or may pose an increased risk of cerebral embolic complications. Thus, in this particular situation we use right radial artery access as it was shown to be very effective and safe in coronary interventions $[6,7]$.

A transradial approach for carotid artery stenting may be a viable alternative for a standard transfemoral technique, although it has some limitations [8]. First, it requires lower profile systems (up to $7 \mathrm{Fr}$ ). Most carotid stents are 5-6 Fr compatible, but only distal EPD for 6-7 Fr access is available at the moment. Second, the radial approach is much more technically demanding in CAS procedures. The unfavorable anatomy can make the passage of a guiding catheter from the radial to the common carotid artery through the aortic arch difficult or even impossible. Thus, prior transradial coronary intervention experience and the use of dedicated devices may increase the chance for success in the carotid territory. Recent data suggest that radial artery access is associated with fewer major bleeding events compared with femoral vascular access, in particular in cases of combined antithrombotic therapy [9]. Moreover, it was recently shown that the overall complication rate of carotid stenting via the radial artery is low, including catheter-induced cerebral embolization $[8,10]$. Early mobilization is another key advantage of the transradial approach especially in older patients undergoing endovascular interventions.

There are similar cases described in the literature [11, 12], but to our knowledge, this is the first description of CAS performed via the transradial approach in Poland.

\section{Conclusions}

Transradial CAS may be a viable alternative to femoral access, especially in patients with severe PAD. However, it is more technically demanding and requires prior transradial coronary intervention experience and the use of dedicated devices.

\section{References}

1. Sudlow $\mathrm{CL}$, Warlow $\mathrm{CP}$. Comparing stroke incidence worldwide: what makes studies comparable? Stroke 1996; 27: 550-558.

2. Ciecierski M, Romaniuk T, Jawień A. Udar mózgu spowodowany miażdżycą tętnic szyjnych [Polish]. Przew Lek 2000; 10: 59-62.

3. Pieniazek P, Musialek P, Kablak-Ziembicka A, et al. Carotid artery stenting with patient- and lesion-tailored selection of the neuroprotection system and stent type: early and 5 -year results from a prospective academic registry of 535 consecutive procedures (TARGET-CAS). J Endovasc Ther 2008; 15: 249-262.

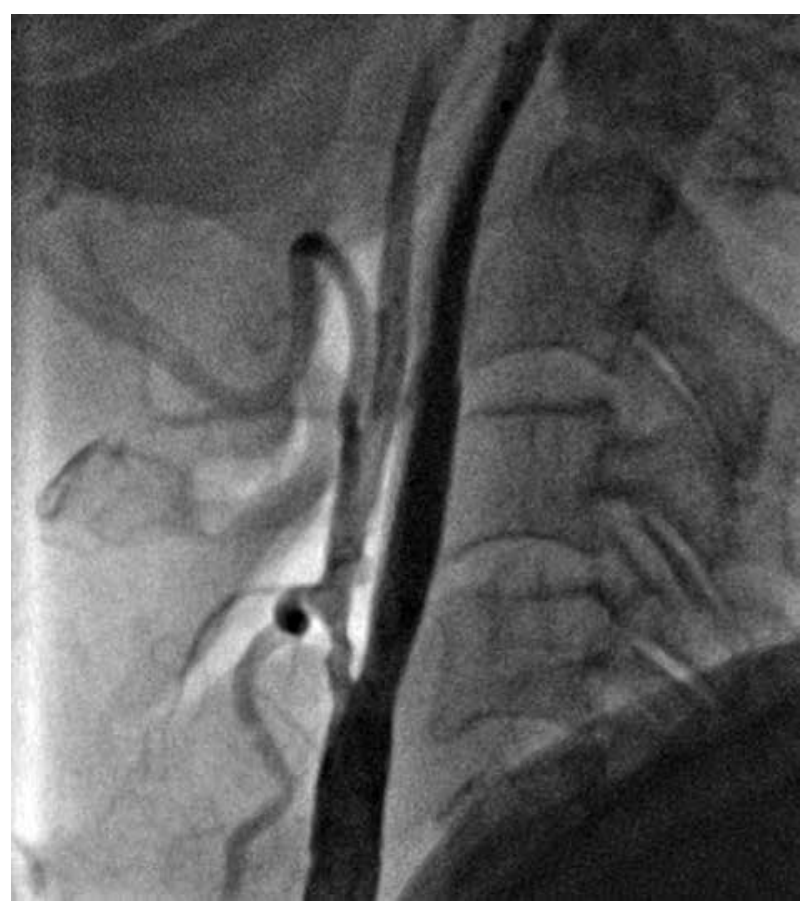

Figure 5. Final angiography showing optimal effect of RICA-CAS

4. Brott TG, Hobson RW, Howard G, et al. Stenting versus endarterectomy for treatment of carotid-artery stenosis. NEJM 2010; 363: 11-23.

5. Silver FL, Mackey A, Clark WM, et al. CREST Investigators safety of stenting and endarterectomy by symptomatic status in the Carotid Revascularization Endarterectomy versus Stenting Trial (CREST) Stroke 2011; 42: 675-680.

6. Mann T, Cubbedu G, Browen J, et al. Stenting in acute coronary syndromes: a comparison of radial versus femoral access sites. J Am Coll Cardiol 1998; 35: 572-576.

7. Louvard Y, Lefevre T, Allain A, et al. Coronary angiography through the radial or femoral approach: the CARAFE study. Catheter Cardiovasc Interv 2001; 52: 181-187.

8. Etxegoien N, Rhyne D, Kedev S, et al. The transradial approach for carotid artery stenting. Catheter Cardiovasc Interv 2012; 80: 1061-1067.

9. Bertrand OF, Belisle P, Joyal D, et al. Comparison of transradial and femoral approaches for percutaneous coronary interventions: a systematic review and hierarchical Bayesian meta-analysis. Am Heart J 2012; 163: 632-648.

10. Faggioli G, Ferri M, Rapezzi C, et al. Atherosclerotic aortic lesions increase the risk of cerebral embolism during carotid stenting in patients with complex aortic arch anatomy. J Vasc Surg 2009; 49: 80-85.

11. Yoo BS, Lee SH, Kim JY, et al. A case of transradial carotid stenting in a patient with total occlusion of distal abdominal aorta. Catheter Cardiovasc Interv 2002; 56: 243-245.

12. Levy El, Kim SH, Bendok BR, et al. Transradial stenting of the cervical internal carotid artery: technical case report. Neurosurgery 2003; 53: 448-452. 